\title{
COMO A COMPUTAÇÃO EM NUVEM PODE AJUDAR AS PEQUENAS E MÉDIAS EMPRESAS NA SUA
}

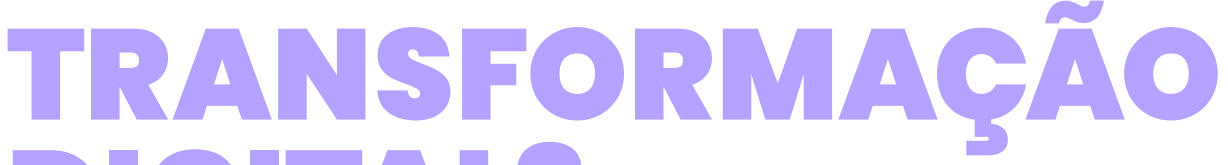
DIGITAL?

Bruno Edmond Rabner e

Shirley Fernandes

De acordo com o portal itforum, $62,5 \%$ das empresas brasileiras investirão entre $10 \%$ e $30 \%$ da sua receita em soluções e transformações digitais. Essa mudança foi alavancada pela pandemia da COVID-19, que apresentou grandes desafios nas rotinas organizacionais e no gerenciamento de serviços, processos e produtos. Os dados fazem parte da pesquisa realizada pela Sambatech e Samba Digital, apontando que $45 \%$ das empresas têm implementado projetos de transformação digital, com destaque para as pequenas e médias organizações que caminham em direção à inovação".

A pesquisa também apresenta as principais tecnologias que lideram esses investimentos em transformação e inovação digitam. São elas: analytics (62\%), computação em nuvem (46\%), arquitetura de sistemas (40\%), inteligência artificial (38\%) e biometria facial (8\%). Essas tecnologias visam solucionar problemas e agilizar processos, explicando, parcialmente, o porquê as empresas estão investindo na transformação digital. Dentre tais tecnologias, podemos destacar a computação em nuvem, que se trata do armazenamento e gerenciamento de dados e informações.
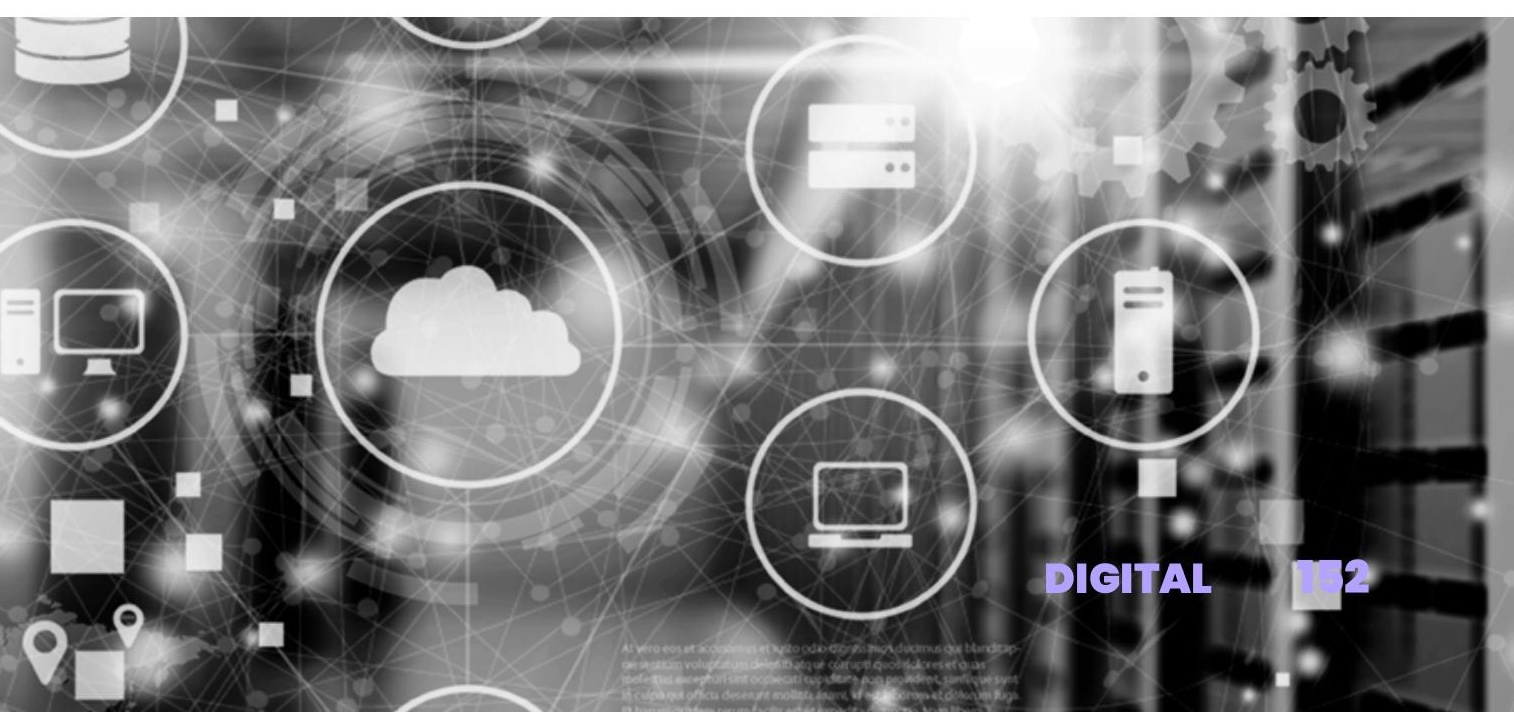
Quando follomos em computcȩão em nuvem, discorremos sebre a infraestrutura de uma empresa servidora perra o armezencimento e processemento de dados. Ela funciona como uma terceirização de hordwares e sofuwdres, epresentondo diverses facilidades para as empresas, como: backup de arquivos, permitindo que a eapacidade de armakenamento aumente; a eriaģão de eamadas de seguranģ, gerando eópias em vários níveis e loecis diferentes; informação ceessivel online e sineronizade, com os arquivos em nuvem podendo ser creessades quando, como e onde o usućrio quiser.

Além disso, há a elíminc ģão da necessid d de de use de dispositivos externos, como pendrives ou eartées de memóric que podem ser perdidos facilmente; $\odot$ compartilhermento de doeumentos, gerrentindo que todes que preciserm a cesser e userr o doeumento tenhalm acesso facilitudo; a seguranģ de dedos, pelo uso de serviços de sistema de segurenģa avanģados; além da reduçẫ de eustos, pois os

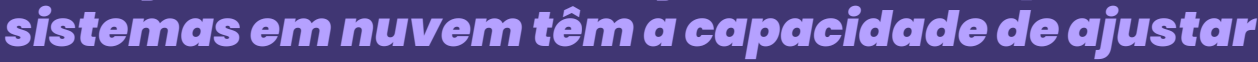
melhor a demanda do eliente ao um prege malis ceessível ejusto.

A pertir do eonjunto de benefícios epresentedes, é possível reflet tir sobre o porquê do cuumento de $46 \%$ do uso da computação em nuvem por empreses no Brasil.

As empresas buscam se reinventar, trazer inovações para os seus processos e agilizar a forma como os seus colaboradores trabalham, interagem e apresentam os resultados. Além disso, elas têm visado cada vez mais se proteger das ameaças digitais, visto que, no país, há um número cada vez mais crescente de crimes e violação de segurança digital. 
Para se ter uma noção, apenas em 2020, foram registradas mais de 156.692 denúncias, um número significativamente superior ao ano anterior, que registrou 75.428 casos contabilizados, de acordo informações do portal $\mathrm{Gl}^{2}$. Os crimes cibernéticos têm acometido diversas empresas. Através de computadores ou redes completas de dispositivos eletrônicos, os cibercriminosos invadem as empresas, roubam os dados e fazem todo um plano elaborado de extorsão para que os dados sejam devolvidos.

Toda essa conjuntura tende a nos sinalizar sobre as mudanças e transformações digitais, pelas quais a sociedade está vivenciando. Essas mudanças não ocorrem do dia para noite, mas a partir de um processo de conscientização, de necessidade e busca por novas formas de trabalho.

Os dados da edição 2020 da DT Index sobre transformação digital demonstram que as empresas passaram a antecipar as iniciativas de transformação digital, visto que $92 \%$ das empresas têm reinventado o seu modelo de negócio devido ao cenário atual ${ }^{3}$.

A pandemia provocada pela COVID-19 apresentou visiveis e significativas mudanças, como o trabalho remoto, impactando também as estratégias e os investimentos das organizações, acelerando e antecipando as mudanças. Nesse caso, em específico, pessoas passam a trabalhar de diferentes localidades, porém, muitas vezes, necessitam utilizar o mesmo banco de dados, atualizar planilhas, compartilhar novos dados. E como fazer isso quando o sistema ainda é físico ou quando não há uma infraestrutura tecnológica preparada para tal funcionalidade?

Diante da relevância do tema para as empresas, que precisam buscar soluções de nuvem para o seu negócio, apresentaremos um caso ilustrativo de aplicação de novas soluções e serviços digitais pela empresa $\mathrm{NI}$ IT, empresa brasileira do setor de Tecnologia da Informação que tem desenvolvido projetos de reestruturação e segurança em ambientes online ${ }^{4}$. A empresa, atenta para o novo mundo e cultura digitais, tem crescido cada vez mais, inclusive através de parcerias com outras empresas de tecnologia, como é o caso da realizada com a Lansys para atender o cliente Artimar.

A Artimar $^{5}$ é uma organização de porte médio do setor da indústria eletroeletrônica. A empresa nasceu pequena, em 1962, com o objetivo de oferecer ao mercado novos recursos e produtos eletrônicos, representando relevantes empresas multinacionais. Entretanto, diante das transformações e mudanças tecnológicas, a organização se deparou com algumas dificuldades de centralização e segurança dos seus documentos no servidor físico. 


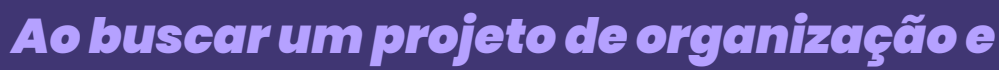

centrallizeção das informaçêes dispersas no coogle, a Artimar demonstra a preoeupaģَo e o interesse com a melhorid des processos de tratemento e seguranģ de informaģ̄o digitul. Essa preocupaçăo, बpresentada pela empresd, e a proeura por melhorics na infraestrutura em nuvem, correspondem aos $52 \%$ de emprescs brasileiras que proeuram por essas soluçôes digitalis, de acerdo eom dados da pesquisa realizada pela DG Latin America IT Investment Trends, em 20216. Além disso, como forma de manter os dados preservades, a organização visa conceder níveis de acesso a os arruivos para cade grupo de colcborador.

Uma vez que a empresa já possuía a licença do Microsoft 365, a N1 IT procurou otimizar o ambiente e os recursos preexistentes dessa licença para a Artimar. Para isso, o cliente foi orientado a utilizar o SharePoint Online, uma plataforma de aplicativos da web que possibilita a criação de uma intranet e, com isso, gerenciar os conteúdos, documentos e demais informações da empresa.

O desafio foi fazer com que cada etapa do processo ocorresse através de um fluxo funcional, contínuo e de fácil manuseio pelos responsáveis na empresa. A proposta de solução digital teve como suporte o uso da nuvem, passando a Artimar a fazer parte de um novo sistema de comunicação digital. Com o processo de implementação digital, foi aperfeiçoada e otimizada a organização dos dados, com a estruturação do processo de uso, o armazenamento e o gerenciamento dos dados. Houve maior controle de acesso pela organização de setores e diferentes tipos de acesso, com aumento do nível de segurança da empresa - anteriormente, a empresa não possuía esse tipo de sistema.

O exemplo da Artimar demonstra como pequenas e médias empresas têm apostado e acreditado na transformação digital, trilhando caminhos em direção ao cenário contemporâneo no qual o uso das tecnologias digitais, a exemplo dos sistemas de nuvem, tem remodelado a comunicação, a interação, o funcionamento do tratamento e o armazenamento de dados. São empresas que buscam por serviços e soluções digitais sob o auxílio de profissionais especializados, com expertise e visão de mercado. 
Alị́s, a visão de merecde pode ser vistc eomo uma des razôes perra que as empresas busquem otimizer os seus processes digitcis sob o uso de serviços e teenologias em nuvem. A transferêneic de dudes e informaçöes para o sistema em nuvem tem compactado um volume gigentesco de dados que as empresas preciscim gerenciar todos os dies. Com uma infraestrutura teenológice e preperrade perra lider com esses dedes, as organizagōes ganham tempo, agilidade, melhor mensuração e visualikação dos números.

Com isso, os benefficios que as soluģöes em nuvem proporcioncm parr es seus usućrios sc̃o muitos: implementação de ceessibilidade em qualquer luger e qualquer dispositive até o errmazencimento, tratcomentoe compartilhamento de dados. Parra as empreses, - serviģo em nuvem é mais do que uma simples plateforma. Permite diminuir eustos e utilizerr serviços avengeddos que dizem respeito à infreestruturc e processemento. Tudo isse por meioda teenologic.

Mas, para além desses benefícios, outros podem ser incluídos nessa lista, como:

- Redução de custos operacionais;

- Maior disponibilidade;

- Mobilidade;

- Simplificação da gestão de Tl;

- Flexibilidade;

- Segurança;

- Produtividade;

- Reforço da escalabilidade operacional;

- Economia de implementação;

- Maior apoio ao uso estratégico de dados. 
Para concluir, a transformação digital já é uma realidade e vem sendo expandida. A cada dia, as empresas e seus gestores entendem os benefícios e os impactos que essa mudança proporcionará no cotidiano das empresas e dos colaboradores.

Neste sentido, frente aos avanços nas tecnologias de computação em nuvem, atualmente o que não faltam são bons motivos para justificar a migração de sistemas empresariais locais para o formato em nuvem e para investir nesse mercado, que também tem apresentado uma demanda no contexto da transformação digital.

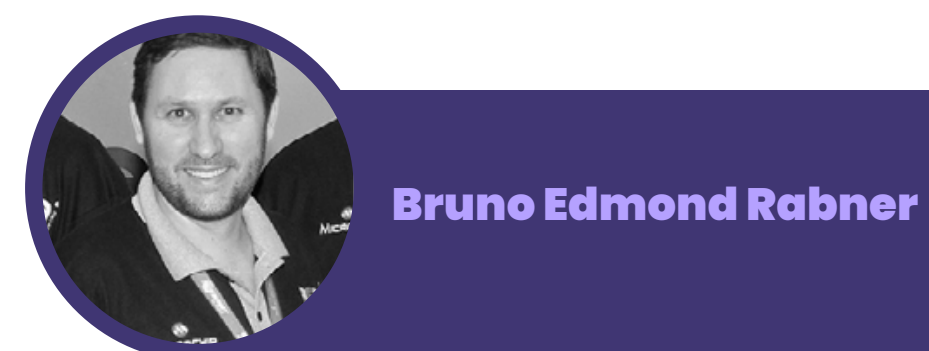

Bacharel em Engenharia Elétrica pelo Instituto Mauá de Tecnologia, com MBA em Marketing pela ESPM. CEO da Artimar, empresa Brasileira desde 1962, representante exclusiva da Microchip há 30 anos na América do Sul, com a missão de Agregar Valor ao Negócio do Cliente com Excelência. André é apaixonado por Tecnologia e Inovação, possui 29 anos de experiencia no mercado de semicondutores, participou ativamente de dezenas de Cursos e Feiras Internacionais nos últimos 15 anos. André está em constante contato com introdução de novas tecnologias no mundo e teve como foco, nos últimos 5 anos, os modelos de negócio de loT, Conectividade, LPWAN e outras iniciativas de tecnologia no mercado Sul-americano.

\section{Shirley Fernandes}

Sócia-diretora Comercial e Marketing da N1 IT Stefanini. Empresária renomada na área de tecnologia, formada em Letras, Personal \& Professional Coach por um dos maiores institutos do Brasil (SBC), Especialista em Gestão de Pessoas há mais de 10 anos, reconhecida dentro e fora do Brasil pela Microsoft por trazer grandes resultados através de sua liderança.
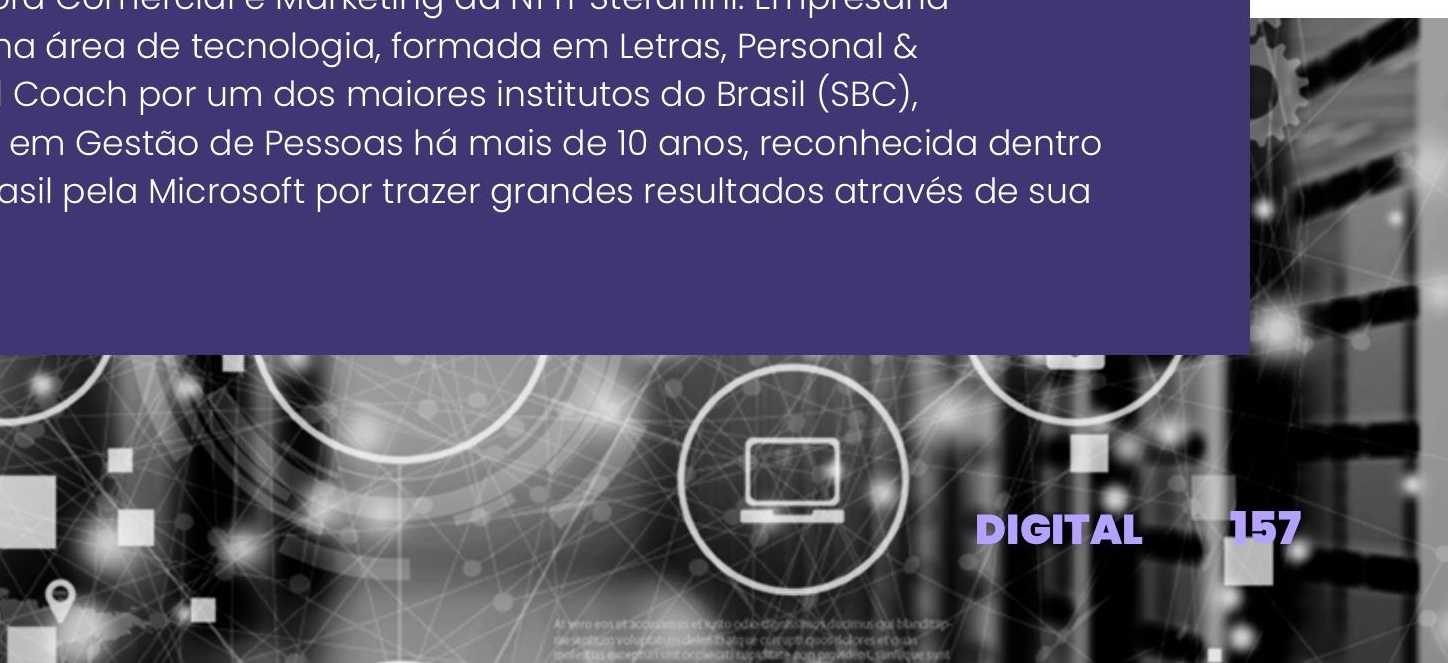


\section{NOTAS}

1 https://itforum.com.br/noticias/empresas-investirao-ate-30-da-receita-emtransformacao-digital-em-2021/ Acesso em 5/10/2021.

2 https:/gl.globo.com/economia/tecnologia/noticia/2021/02/09/numero-dedenuncias-de-crimes-cometidos-pela-internet-mais-que-dobra-em-2020. ghtml. Acesso em 5/10/2021.

3 https://www.delltechnologies.com/pt-br/perspectives/digital-transformationindex.htm. Acesso em 5/10/21.

$4 \mathrm{https} / /$ www.delltechnologies.com/pt-br/perspectives/digital-transformationindex.htm. Acesso em 5/10/21.

5 https://www.artimar.com.br/2022/

6 https://canaltech.com.br/computacao-na-nuvem/segundo-idc-39-dasempresas-da-america-latina-vao-investir-em-nuvem-188312/

\section{REFERÊNCIAS}

https://mittechreview.com.br/raio-x-da-transformacao-digital-no-brasil-em2021-principais-dados-e-insights/. Acesso em: 01/10/2021.

https://canaltech.com.br/computacao-na-nuvem/segundo-idc-39-dasempresas-da-america-latina-vao-investir-em-nuvem-188312/. Acesso em: 05/10/2021.

https://forbes.com.br/forbes-tech/2020/11/pandemia-faz-875-das-empresasno-brasil-aceleraram-projetos-de-transformacao-digital/. Acesso em:

06/10/2021. 